\title{
The association between performance parameters of physical fitness and postoperative outcomes in patients undergoing colorectal surgery
}

Citation for published version (APA):

Heldens, A. F. J. M., Bongers, B. C., Lenssen, A. F., Stassen, L. P. S., Buhre, W. F., \& van Meeteren, N. L. U. (2017). The association between performance parameters of physical fitness and postoperative outcomes in patients undergoing colorectal surgery: An evaluation of care data. European Journal of Surgical Oncology, 43(11), 2084-2092. https://doi.org/10.1016/j.ejso.2017.08.012

Document status and date:

Published: 01/11/2017

DOI:

10.1016/j.ejso.2017.08.012

Document Version:

Publisher's PDF, also known as Version of record

Document license:

Taverne

Please check the document version of this publication:

- A submitted manuscript is the version of the article upon submission and before peer-review. There can be important differences between the submitted version and the official published version of record.

People interested in the research are advised to contact the author for the final version of the publication, or visit the DOI to the publisher's website.

- The final author version and the galley proof are versions of the publication after peer review.

- The final published version features the final layout of the paper including the volume, issue and page numbers.

Link to publication

\footnotetext{
General rights rights.

- You may freely distribute the URL identifying the publication in the public portal. please follow below link for the End User Agreement:

www.umlib.nl/taverne-license

Take down policy

If you believe that this document breaches copyright please contact us at:

repository@maastrichtuniversity.nl

providing details and we will investigate your claim.
}

Copyright and moral rights for the publications made accessible in the public portal are retained by the authors and/or other copyright owners and it is a condition of accessing publications that users recognise and abide by the legal requirements associated with these

- Users may download and print one copy of any publication from the public portal for the purpose of private study or research.

- You may not further distribute the material or use it for any profit-making activity or commercial gain

If the publication is distributed under the terms of Article 25fa of the Dutch Copyright Act, indicated by the "Taverne" license above, 


\title{
The association between performance parameters of physical fitness and postoperative outcomes in patients undergoing colorectal surgery: An evaluation of care data
}

\author{
A.F.J.M. Heldens ${ }^{\mathrm{a}, \mathrm{b}, *}$, B.C. Bongers ${ }^{\mathrm{a}}$, A.F. Lenssen ${ }^{\mathrm{b}}$, \\ L.P.S. Stassen ${ }^{\mathrm{c}}$, W.F. Buhre ${ }^{\mathrm{d}}$, N.L.U. van Meeteren ${ }^{\mathrm{a}, \mathrm{e}}$ \\ ${ }^{a}$ Department of Epidemiology, Care and Public Health Research Institute (CAPHRI), Maastricht University, \\ Maastricht, The Netherlands \\ ${ }^{\mathrm{b}}$ Department of Physical Therapy, Maastricht University Medical Center, Maastricht, The Netherlands \\ ${ }^{\mathrm{c}}$ Department of Surgery, Maastricht University Medical Center, Maastricht, The Netherlands \\ ${ }^{\mathrm{d}}$ Department of Anesthesiology and Pain Therapy, Maastricht University Medical Center, Maastricht, The \\ Netherlands \\ ${ }^{\mathrm{e}}$ Top Sector Life Sciences and Health (Health Holland), The Hague, The Netherlands
}

Accepted 21 August 2017

Available online 7 September 2017

\begin{abstract}
Background: Preoperative cardiorespiratory fitness, as measured by cardiopulmonary testing or estimated using the less sophisticated incremental shuttle walk test, timed up-and-go test or stair climb test is known to be associated with postoperative outcome. This study aimed to evaluate whether parameters of physical fitness are associated with postoperative outcome in patients with colorectal cancer scheduled for elective resection.

Patients and Methods: Perioperative data of patients who underwent colorectal resection at Maastricht University Medical Center were retrospectively analyzed. Preoperative variables (e.g., age, body mass index, comorbidities, physical fitness, tumour characteristics, neoadjuvant treatment, American Society of Anesthesiologists score, level of perceived fatigue and nutritional status) were compared with postoperative outcomes.

Results: Out of 80 consecutive cases, 75 (93.8\%) were available for analysis (57.3\% male, median \pm interquartile range age $69.2 \pm 11.7$ years). A higher Charlson comorbidity index (odds ratio (OR) of 1.604, 95\% confidence interval (CI) 1.120-2.296), worse functional exercise capacity (in meters, OR of $0.995,95 \%$ CI $0.991-1.000$ ), a lower physical activity level (in min/day, OR of $0.994,95 \%$ CI 0.988-1.000), and a higher level of perceived fatigue (OR of 1.047, 95\% CI 1.016-1.078), were associated with a slower time to recovery of physical functioning. A better functional exercise capacity was associated with a lower OR (OR of 0.995 , 95\% CI 0.991-1.000) for nonsurgical complications.

Conclusion: There is an association between preoperative parameters and postoperative outcomes in patients with colorectal cancer scheduled for resection. Patients benefit from an optimal preoperative physical fitness level. Specific interventions can target this physical fitness level.

(C) 2017 Elsevier Ltd, BASO The Association for Cancer Surgery, and the European Society of Surgical Oncology. All rights reserved.
\end{abstract}

Keywords: Physical fitness; Exercise testing; Risk stratification; Colorectal cancer; Colorectal resection

\footnotetext{
* Corresponding author. Department of Physical Therapy, Maastricht University Medical Center, Postal address: P.O. Box 5800, 6202, AZ, Maastricht, The Netherlands.

E-mail addresses: aniek.heldens@mumc.nl (A.F.J.M. Heldens), bart.bongers@maastrichtuniversity.nl (B.C. Bongers), af.lenssen@mumc.nl (A.F. Lenssen), lps.stassen@mumc.nl (L.P.S. Stassen), wolfgang.buhre@ mumc.nl (W.F. Buhre), meeteren@health-holland.com (N.L.U. van Meeteren).
}

\section{Introduction}

In the Netherlands, patients with signs of colorectal cancer are identified via the national screening program for colorectal cancer (see www.bevolkingsonderzoekzuid.nl) or after referral of the general practitioner. After confirmation of the diagnosis and the decision for surgery, most of 
the patients (rectal cancer; 99.0\%, colon cancer; 87.0\%) undergo elective colorectal resection [1]. A smaller proportion of patients (rectal cancer; 1.0\%, colon cancer; 13.0\%) requires acute surgery [1]. After the decision for elective surgery, pre-assessment by the anesthesiologist and the physical therapist for medical conditions and physical fitness is scheduled (see Fig. 1 that illustrates the patient journey at the Maastricht University Medical Center).

Major colorectal surgery is significantly associated with morbidity and even mortality [2,3]. Outcome after major surgery depends on several factors such as perioperative care, neoadjuvant treatment, and also physical fitness. Preoperative cardiorespiratory fitness has been reported to have a consistent positive relation with postoperative outcome in abdominal surgery [4-8]. A poor cardiorespiratory fitness, as measured by a maximal cardiopulmonary exercise test, indicates a reduced physiological reserve, which can contribute to a complicated postoperative time course including morbidity and mortality in patients with lower and upper gastrointestinal cancer, respectively [5,9]. Patients with an increased preoperative level of cardiorespiratory fitness may have a greater physiological reserve to better cope with surgical stress that significantly increases the metabolic demand after surgery [7].

In most Dutch hospitals, performing a preoperative cardiopulmonary exercise test for risk stratification is not part of standard care for patients undergoing major abdominal surgery. However, performance at less sophisticated physical fitness tests has been found to be related to postoperative outcomes as well. Studies of Nutt et al. [10] and Struthers et al. [11] showed that the incremental shuttle walk test (iSWT) can serve as an indicator of postoperative risk in patients undergoing abdominal surgery. The timed up-and-go (TUG) test [12] is identified as a predictor for postoperative complications in patients undergoing elective surgery (for breast cancer and gastrointestinal malignancies). Other studies identified the stair-climbing test as predictor for postoperative complications in elective abdominal surgery [13] and in surgical resection for nonsmall cell lung cancer [14]. Alternative physical performance tests that provide information about the patient's physical fitness may therefore also be appropriate tools to perform preoperative risk stratification in several surgical populations.

The aim of this study was therefore to evaluate whether preoperative performance parameters of physical fitness are associated with postoperative outcomes in patients with colorectal cancer scheduled for elective colorectal resection. If specific preoperative parameters are associated with postoperative outcome, these variables may be targeted with preoperative interventions in order improve postoperative outcome, trajectories that were already executed by others $[15,16]$.

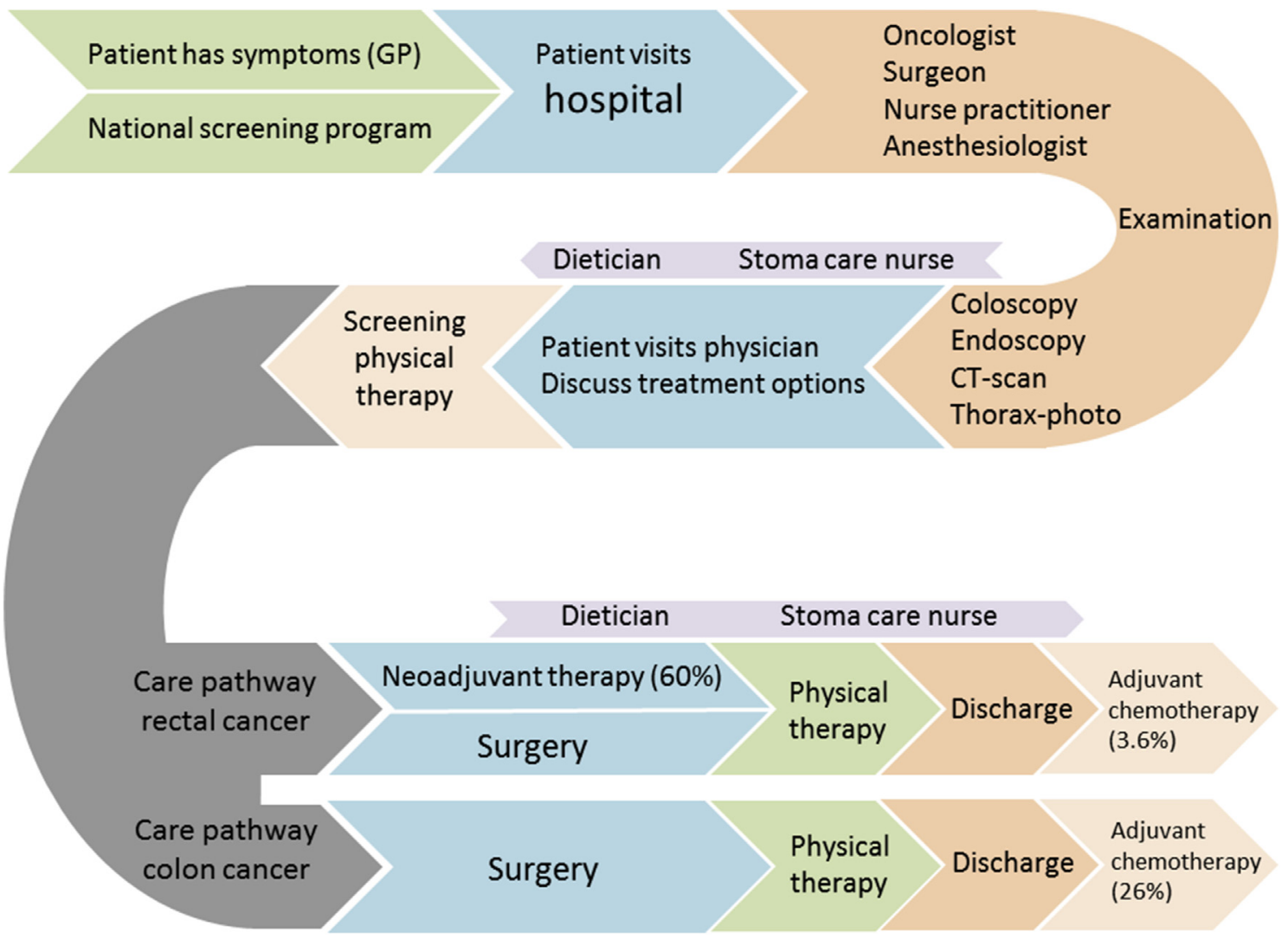

Fig. 1. Patient journey for colon and rectal cancer at our hospital. 


\section{Patients and methods}

\section{Participants}

Patients diagnosed with colorectal cancer planned for elective colorectal resection at the Maastricht University Medical Center (Maastricht UMC + ) are being monitored pre- and postoperatively for their physical fitness as part of usual care. For this study, data sampling was performed between January 2015 and December 2015. All consecutive patients $>18$ years of age who underwent elective colorectal resection for cancer and who had no objection for the use of their usual care data for research purposes were included. When essential data about postoperative outcomes was missing, the data of that patient was excluded from analysis. The medical ethical committee of the Maastricht UMC + decided (15-4-234) that this study met the ethical policies of the Maastricht $\mathrm{UMC}+$ and the regulations of the Dutch government.

\section{Preoperative screening}

After the decision for elective colorectal resection, patients consulted the hospital physical therapist as soon as possible for a preoperative screening of physical fitness. During the consultation, patients were educated about the importance of adequate physical fitness to better meet the metabolic demands of major surgery. Patients received standard advice about physical activity throughout the preoperative period. Additionally, patients received information about the content and expectations of postoperative physical therapy treatment during hospitalization.

\section{Outcome variables}

Time to recovery of physical functioning (measured by the modified Iowa levels of assistance scale - mILAS [17]) and data on surgical complications (surgical and non-surgical) were collected from patient files. Time to recovery of physical functioning was defined as the time between the day of surgery and the day at which patients reached a mILAS score of 0 (in days). Data on postoperative complications were registered with the use of the Clavien-Dindo classification [18].

\section{Predictive variables}

Patient characteristics at time of surgery and treatment details were obtained from electronic patient files. The potential predictors age, body mass index, identification via the national screening program or general practitioner, Charlson comorbidity index, tumour, node, metastasis stage, additional neoadjuvant treatment, American Society of Anesthesiologists score, smoking status, nutritional status (short nutritional assessment questionnaire), level of perceived fatigue (multidimensional fatigue index), and operation type were collected. Data from the preoperative screening of physical fitness (functional exercise capacity, muscle strength, functional mobility, and the level of physical activity) were also included.

\section{Functional exercise capacity}

To measure functional exercise capacity, the modified protocol of the iSWT was used [19], with the maximum walking distance as primary outcome measure. The modified protocol of the iSWT is an extension of the original twelvelevel iSWT, with the exact same instructions as the original test [20]. The test starts with a walking speed of $1.8 \mathrm{~km} / \mathrm{h}$. Every level has a duration of $1 \mathrm{~min}$ and the walking speed increases with $0.6 \mathrm{~km} / \mathrm{h}$ per level. The maximum walking speed is $10.3 \mathrm{~km} / \mathrm{h}$ during level 15 , in which subjects are allowed to run. Prior to the walking test, standardized instructions were given and the patients were encouraged to walk as long as possible. Heart rate was monitored during the test. The participants had to move around two markers over a 10-m course in time with audio signals from a pre-recorded tape. The test was terminated when the patient could not reach the markers on time on two consecutive audio signals. The use of a walking aid, orthopedic shoes or orthoses was permitted. The test was performed under the close surveillance of an experienced hospital physical therapist. The test-retest reliability for the shuttle walk test varies from 0.760 to 0.990 [21].

\section{Muscle strength}

Handgrip strength as measured with a hand held dynamometer (JAMAR ${ }^{\circledR}$ Hydraulic Hand Dynamometer, JAMAR, Patterson Medical Holdings, Inc., Illinois, USA) was used to provide an indication of the patient's overall muscle strength. Patients were seated in a chair with their elbow flexed at $90^{\circ}$ and the forearm in the neutral position without any arm support from the chair. The patient performed the test three times with the dominant hand, of which the highest value $(\mathrm{kg})$ was reported [22]. The assessment of handgrip strength measured with the Jamar dynamometer is a reliable method (intraclass correlation coefficient values $0.85-0.98$ ) [23].

\section{Functional mobility}

Functional mobility was measured with the TUG test, in which the time needed to rise from a chair, walk $3 \mathrm{~m}$, walk back to the chair, and sit down again, was measured [24]. After one practice trial, the patient was asked to perform the test three times, of which the fastest time (s) was reported.

\section{Level of physical activity}

Patients were asked about the frequency, duration, and intensity of various physical activities (total minutes of walking, cycling, gardening, household activities, and sport activities) during the two weeks before the preoperative screening with the LASA Physical Activity Questionnaire 
(LAPAQ) [25]. The total amount of physical activity was converted in minutes of physical activity per day (min/day).

\section{Usual care pathway}

Postoperative care was similar for all patients, regardless of the surgical procedure. All patients participated in postoperative physical therapy (started at postoperative day 1), in which recovery of physical functioning was monitored using the mILAS [17]. The mILAS assesses the capability of patients to perform several activities of daily living (transfer from supine position to sitting and vice versa, sit-to-stand, walking, and stair climbing) and rates the amount of assistance needed. Postoperative physical therapy consisted of airway clearing exercises, strength exercises, practicing transfers, walking, stair climbing (when necessary for independent functioning at home), and improving muscle function and cardiorespiratory capacity.

\section{Data analysis}

The Statistical Package for the Social Sciences for Windows (version 23.0; IBM, SPSS Inc., Chicago, IL, USA) was used for statistical analysis. For all variables, normality was tested with the Kolmogorov-Smirnov test. Data were presented as median and interquartile range (IQR), when the data were not normally distributed. Data on postoperative complications were divided into subgroups (total complications, surgical complications, and non-surgical complications $)$ and dichotomized $(0=$ absent, $1=$ present $)$. Data on time to recovery of physical functioning was also dichotomized $(0=$ recovery of physical functioning in $\leq 4$ days, $1=$ recovery of physical functioning in $\geq 5$ days; as the median time to recovery of physical functioning in the patient population of the current study equaled four days). Additionally, potential predictors were added in univariate logistic regression analysis (enter method) to explore the association between individual independent predictors and postoperative outcome variables. Receiver operating characteristic (ROC) analysis was used to establish optimal threshold values of functional exercise capacity as measured with the iSWT distance to predict non-surgical complications. Finally, a multivariate logistic regression analysis was performed to construct a model which explains the variance in outcome variables. To select potential predictor variables for the regression model, a $P$-value of 0.200 was used. For the other statistical analyses a $P$-value $<0.05$ was considered statistically significant.

\section{Results}

Preoperative data of 80 patients with colorectal cancer were available for analysis. Of these patients, five (6.3\%) were excluded because of missing postoperative data (data not available in the database because the nature of the tumour; $\mathrm{n}=4$, and missing data about the physical therapy treatment; $\mathrm{n}=1$ ). This left 75 cases $(93.8 \%)$ for analysis, 43 men (57.3\%) and 32 women (42.7\%) with a median \pm IQR age of $69.2 \pm 11.7$ years. Of these patients, $39(52.0 \%)$ were identified via the Dutch national screening program for colorectal cancer. These patients had a statistically significant higher muscle strength $(39.3 \pm 18.4$ vs $30.0 \pm 22.7 \mathrm{~kg} ; P=0.032)$ and a statistically significant lower level of perceived fatigue $(27.0 \pm 20.0$ vs $41.0 \pm 34.8 ; P=0.005)$. There was also a statistically significant difference in clinical tumour stages (cT1, cN1 and $\mathrm{cN} 2$ ) between these groups. Table 1 shows patient characteristics and baseline values. Treatment details and postoperative outcomes are summarized in Table 2.

\section{Postoperative complications}

Postoperatively, 27 complications (36.0\%) were registered, of which 20 (74.1\%) were surgical (e.g., anastomotic leakage) and seven (25.9\%) were non-surgical (e.g., pulmonary complications). Five patients $(6.7 \%)$ suffered from anastomotic leakage, of which one patient received preoperative radiation (in combination with chemotherapy) and two patients had preoperative anemia. Redo-surgery was necessary in 9 of the 20 patients with surgical complications $(45.0 \%)$. According to the Clavien-Dindo classification there were sixteen $(59.3 \%)$ grade I, one $(3.7 \%)$ grade II, seven $(25.9 \%)$ grade III, one $(3.7 \%)$ grade IV and two (7.4\%) grade $\mathrm{V}$ complications. The latter two patients died at the hospital due to complications following redosurgery for anastomotic leakage (overall mortality rate of $2.7 \%)$. Eight (10.7\%) readmissions were reported.

\section{Time to recovery of physical functioning}

Median $\pm \mathrm{IQR}$ time to recovery of physical functioning was $4.0 \pm 3.0$ days. When data were clustered according to type of surgical procedure, transabdominal laparoscopic surgery $(\mathrm{n}=61)$ versus transabdominal open surgery $(\mathrm{n}=14)$, a statistically significant difference in time to recovery of physical functioning $(4.0 \pm 2.0$ versus $8.0 \pm 8.25$ days; $P<0.001$ ) was observed. Additionally, patients that were identified via the national screening program had a statistically significant faster time to recovery of physical functioning $(4.0 \pm 2.0$ vs $5.5 \pm 5.8$ days; $P=0.011)$. A separate analysis showed no difference in time to recovery of physical functioning between laparoscopic and open surgery in the group of patients that was identified via the national screening program. In the group of patients that was identified via the general practitioner there was a statistically significant difference found between laparoscopic and open surgery (time to recovery of physical functioning of $10.0 \pm 8.5$ vs $4.0 \pm 3.0$ days; $P=0.006$ ).

Results of the univariate logistic regression are shown in Table 3. Logistic regression analysis showed that functional exercise capacity, nutritional status, level of 
Table 1

Participant characteristics.

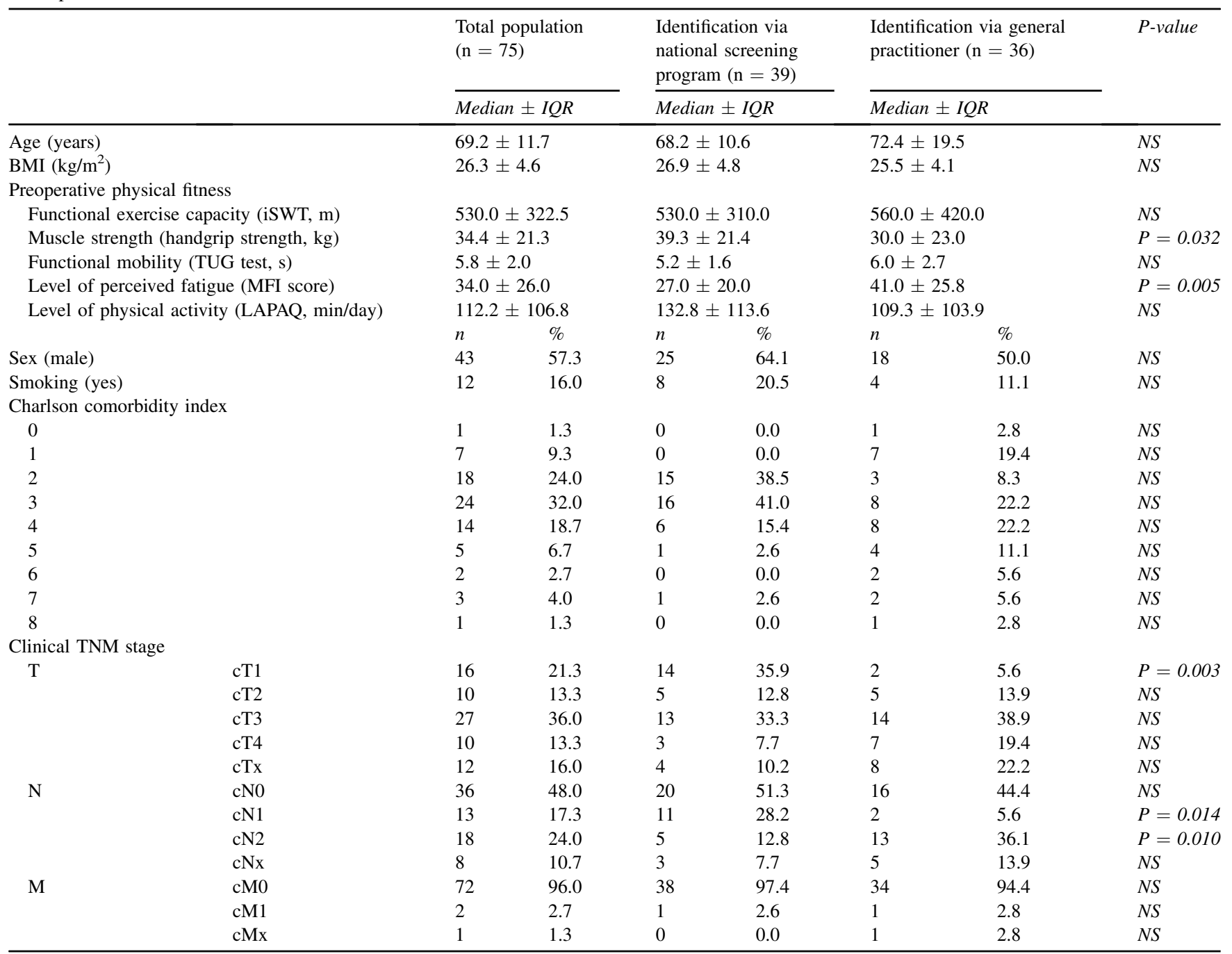

Abbreviations: $\mathrm{BMI}=$ Body mass index $\left(\mathrm{kg} / \mathrm{m}^{2}\right) ; \mathrm{IQR}=$ interquartile range; iSWT = incremental shuttle walk test; LAPAQ $=\mathrm{LASA}$ physical activity questionnaire; MFI = Multidimensional fatigue index; NS = not statistically significant; TNM = Tumour, Node, Metastasis; TUG = timed up-and-go.

perceived fatigue score, and muscle strength were independent predictors of non-surgical complications. The model with functional exercise capacity predicted $14.8 \%$ of the variance in non-surgical complications (pseudo $\mathrm{R}^{2}$ ). A higher functional exercise capacity and higher muscle strength were associated with smaller odds ratio's (ORs) for non-surgical complications. If walking distance on the iSWT increased by $1 \mathrm{~m}$, the odds of experiencing non-surgical complications decreased by 0.005 . Hence, if the preoperative walking distance increased by $100 \mathrm{~m}$, the odds of experiencing a non-surgical complication decreases with 0.5 . Patients with a worse nutritional status and a higher level of perceived fatigue were more likely to experience non-surgical complications. ROC analysis depicted in Fig. 2 shows the value of the iSWT to predict non-surgical complications. The area under the curve (95\% confidence interval) was 0.755 (0.592-0.918, $P=0.027)$.
Further analysis showed that Charlson comorbidity index, identification via the national screening program, age, functional exercise capacity, functional mobility, level of perceived fatigue, and level of physical activity were independent predictors of a longer time to recovery of physical functioning. The OR for functional mobility was 1.274 , which indicates that each 1-s increase in TUG test outcome increased the odds of having a prolonged time to recovery of physical functioning by 0.274 . The model with the level of perceived fatigue had a pseudo $\mathrm{R}^{2}$ of $19.3 \%$. The American Society of Anesthesiologists score was not related to postoperative outcomes.

Multivariate logistic regression analysis gave additional value in the prediction of postoperative time to recovery of physical functioning. The level of perceived fatigue (OR of $1.044,95 \%$ confidence interval (CI) of 1.013-1.076) and physical activity level (OR of $0.995,95 \%$ CI of $0.989-1.002$ ) were associated with $22.8 \%$ of the variance 
Table 2

Participant treatment details and postoperative outcomes.

\begin{tabular}{|c|c|c|c|c|c|c|c|c|}
\hline & & \multicolumn{2}{|c|}{$\begin{array}{l}\text { Total population } \\
(\mathrm{n}=75)\end{array}$} & \multicolumn{2}{|c|}{$\begin{array}{l}\text { Identification via } \\
\text { national screening } \\
\text { program }(\mathrm{n}=39)\end{array}$} & \multicolumn{2}{|c|}{$\begin{array}{l}\text { Identification via general } \\
\text { practitioner }(\mathrm{n}=36)\end{array}$} & \multirow[t]{2}{*}{$P$-value } \\
\hline & & $n$ & $\%$ & $n$ & $\%$ & $n$ & $\%$ & \\
\hline \multicolumn{9}{|c|}{ Tumour distance from anal verge $(\mathrm{cm})$} \\
\hline \multicolumn{2}{|c|}{$<5.0$} & 5 & 6.7 & 1 & 2.6 & 4 & 11.1 & $N S$ \\
\hline \multicolumn{2}{|c|}{$5.1-10.0$} & 15 & 20.0 & 5 & 12.8 & 10 & 27.8 & $N S$ \\
\hline \multicolumn{2}{|c|}{$>10.1$} & 55 & 73.3 & 33 & 84.6 & 22 & 61.1 & $N S$ \\
\hline \multicolumn{9}{|c|}{ Operation type } \\
\hline \multicolumn{2}{|c|}{ Transabdominal laparoscopic } & 61 & 81.3 & 35 & 89.7 & 26 & 72.2 & $N S$ \\
\hline \multicolumn{2}{|c|}{ Transabdominal open } & 14 & 18.7 & 4 & 10.3 & 10 & 27.8 & $N S$ \\
\hline \multicolumn{9}{|c|}{ Surgery } \\
\hline \multicolumn{2}{|c|}{ Extended right hemicolectomy } & 19 & 25.3 & 8 & 20.5 & 10 & 27.8 & $N S$ \\
\hline \multicolumn{2}{|c|}{ Transversum resection } & 1 & 1.3 & 0 & 0.0 & 1 & 2.8 & $N S$ \\
\hline \multicolumn{2}{|c|}{ Extended left hemicolectomy } & 6 & 8.0 & 5 & 12.8 & 1 & 2.8 & $N S$ \\
\hline \multicolumn{2}{|c|}{ Low anterior resection } & 44 & 58.7 & 24 & 61.5 & 21 & 58.3 & $N S$ \\
\hline \multicolumn{2}{|c|}{ Abdomino-perianal resection } & 5 & 6.7 & 2 & 5.1 & 3 & 8.3 & $N S$ \\
\hline \multicolumn{9}{|c|}{ Pathological TNM stage } \\
\hline \multirow[t]{5}{*}{$\mathrm{T}$} & pT0 & 0 & 0.0 & 0 & 0.0 & 0 & 0.0 & $N S$ \\
\hline & pT1 & 22 & 29.3 & 18 & 46.2 & 4 & 11.1 & $N S$ \\
\hline & pT2 & 21 & 28.0 & 9 & 23.1 & 12 & 33.3 & $N S$ \\
\hline & pT3 & 27 & 36.0 & 11 & 28.2 & 16 & 44.4 & $N S$ \\
\hline & pT4 & 5 & 6.7 & 1 & 2.6 & 4 & 11.1 & $N S$ \\
\hline \multirow[t]{3}{*}{$\mathrm{N}$} & pNO & 49 & 65.3 & 24 & 61.5 & 27 & 75.0 & $N S$ \\
\hline & $\mathrm{pN} 1$ & 23 & 30.7 & 15 & 38.5 & 8 & 22.2 & $N S$ \\
\hline & $\mathrm{pN} 2$ & 3 & 4.0 & 0 & 0.0 & 3 & 8.3 & $N S$ \\
\hline \multirow[t]{3}{*}{ M } & $\mathrm{pM} 0$ & 68 & 90.7 & 38 & 97.4 & 30 & 83.3 & $N S$ \\
\hline & pM1 & 3 & 4.0 & 1 & 2.6 & 2 & 5.6 & $N S$ \\
\hline & $\mathrm{pMx}$ & 4 & 5.3 & 0 & 0.0 & 4 & 13.9 & $N S$ \\
\hline \multicolumn{9}{|c|}{$\begin{array}{l}\text { Neoadjuvant treatment } \\
\text { Radiation }\end{array}$} \\
\hline \multicolumn{2}{|c|}{ Chemoradiation } & 15 & 20.0 & 4 & 10.3 & 11 & 15.9 & $N S$ \\
\hline \multicolumn{2}{|c|}{ Short term radiation } & 3 & 4.0 & 2 & 5.1 & 1 & 2.8 & $N S$ \\
\hline Che & & 10 & 13.3 & 3 & 7.7 & 7 & 19.4 & $N S$ \\
\hline ASA : & & & & & & & & \\
\hline I & & 13 & 17.3 & 8 & 20.5 & 5 & 13.9 & $N S$ \\
\hline II & & 46 & 61.3 & 25 & 64.1 & 21 & 58.3 & $N S$ \\
\hline III & & 16 & 21.3 & 6 & 15.4 & 10 & 27.8 & $N S$ \\
\hline Postop & & & & & & & & \\
\hline Con & & 27 & 36.0 & 12 & 30.8 & 15 & 41.7 & $N S$ \\
\hline Rea & & 8 & 10.7 & 3 & 7.7 & 5 & 13.9 & $N S$ \\
\hline Mo & & 2 & 2.7 & 1 & 2.6 & 1 & 2.8 & $N S$ \\
\hline & & $\mathrm{Med}$ & $I Q R$ & $\mathrm{Mec}$ & $I Q R$ & & & \\
\hline Len & & 6.0 & & 5.0 & & 7.5 & & $P=0.009$ \\
\hline Tim & cal functioning (days) & 4.0 & & 4.0 & & 5.5 & & $P=0.011$ \\
\hline
\end{tabular}

Abbreviations: ASA = American Society of Anaesthesiologists score; NS = not statistically significant; TNM = Tumour, Node, Metastasis.

in time to recovery of physical functioning. Patients with a higher level of perceived fatigue and a lower level of preoperative physical activity were more likely to have a longer time to recovery of physical functioning. Surgical complications and readmissions could not be predicted with the current data set and statistical analyses.

\section{Discussion}

The aim of this study was to evaluate the associations between preoperative parameters of physical fitness and postoperative outcome in patients with colorectal cancer scheduled for elective colorectal resection. The results of this study show that several preoperative parameters are associated with the patient's postoperative outcome. Functional exercise capacity, functional mobility, level of perceived fatigue, and level of physical activity were independent predictors of a shorter time to recovery of physical functioning. Preoperative physical functioning (functional exercise capacity, muscle strength, level of perceived fatigue) and nutritional status were associated with the presence of non-surgical complications. Patients with a better preoperative level of physical fitness are less likely to experience non-surgical complications. In addition, patients 
Table 3

Results of univariate logistic regression analysis.

\begin{tabular}{|c|c|c|c|c|c|c|}
\hline Outcome variable & Predictor variable & $\mathrm{B}$ & Wald & P-value & Odds ratio $(\mathrm{OR})$ & Nagelkerke $\mathrm{R}^{2}$ \\
\hline \multirow{4}{*}{$\begin{array}{l}\text { Non-surgical complications } \\
\qquad(0=\text { absent, } 1=\text { present })\end{array}$} & Functional exercise capacity (iSWT, m) & -0.005 & 3.961 & 0.047 & $0.995(0.991-1.000)$ & 0.148 \\
\hline & $\begin{array}{l}\text { Nutritional status (short nutritional } \\
\text { assessment questionnaire) }{ }^{\mathrm{a}}\end{array}$ & 0.291 & 2.118 & 0.146 & $1.338(0.904-1.981)$ & 0.054 \\
\hline & Level of perceived fatigue (MFI score) ${ }^{\mathrm{b}}$ & 0.034 & 4.006 & 0.045 & $1.034(1.001-1.069)$ & 0.108 \\
\hline & Muscle strength (handgrip strength, kg) & -0.051 & 2.149 & 0.143 & $0.951(0.888-1.017)$ & 0.069 \\
\hline \multirow{7}{*}{$\begin{array}{l}\text { Time to recovery of physical } \\
\text { functioning }(0=\text { recovery } \\
\text { of physical functioning in } \leq \\
4 \text { days, } 1=\text { recovery of } \\
\text { physical functioning in } \geq \\
5 \text { days) }\end{array}$} & Charlson comorbidity index & 0.472 & 6.655 & 0.010 & $1.604(1.120-2.296)$ & 0.137 \\
\hline & National screening program (yes or no) & 0.916 & 3.720 & 0.054 & $2.500(0.985-6.344)$ & 0.066 \\
\hline & Age (years) & 0.060 & 3.956 & 0.047 & $1.061(1.001-1.126)$ & 0.074 \\
\hline & Functional exercise capacity (iSWT, m) & -0.002 & 4.577 & 0.032 & $0.998(0.996-1.000)$ & 0.094 \\
\hline & Functional mobility (TUG test, s) ${ }^{\mathrm{c}}$ & 0.242 & 3.152 & 0.076 & $1.274(0.975-1.664)$ & 0.065 \\
\hline & Level of perceived fatigue (MFI score) ${ }^{\mathrm{b}}$ & 0.046 & 8.970 & 0.003 & $1.047(1.016-1.078)$ & 0.193 \\
\hline & Level of physical activity (LAPAQ, min/day) & -0.006 & 3.714 & 0.054 & $0.994(0.988-1.000)$ & 0.075 \\
\hline
\end{tabular}

Abbreviations: iSWT $=$ incremental shuttle walk test; LAPAQ = LASA physical activity questionnaire; MFI = Multidimensional fatigue index; TUG $=$ timed up-and-go.

a A higher score means a worse nutritional status.

b A higher score means a higher level of perceived fatigue.

c A higher score means a worse functional mobility.

with a worse preoperative nutritional status were more likely to experience non-surgical complications.

A ROC analysis of our data showed a value of $290 \mathrm{~m}$ on iSWT as the most optimal threshold to predict non-surgical complications with a sensitivity of 0.570 and a specificity of 0.890 . Previous literature on the iSWT shows a threshold of $360 \mathrm{~m} \mathrm{[11]} \mathrm{and} 250 \mathrm{~m} \mathrm{[10],} \mathrm{respectively} \mathrm{to} \mathrm{identify} \mathrm{pa-}$ tients at risk for postoperative complications in abdominal surgery. A higher sensitivity at the ROC analysis (which is often more desirable in daily practice) provides a value of $515 \mathrm{~m}$ on iSWT as threshold to predict non-surgical complications with a sensitivity of 0.857 and a specificity of 0.554 . Consequently, postoperative outcomes were better in patients with a preoperative walking distance of $515 \mathrm{~m}$ or higher.

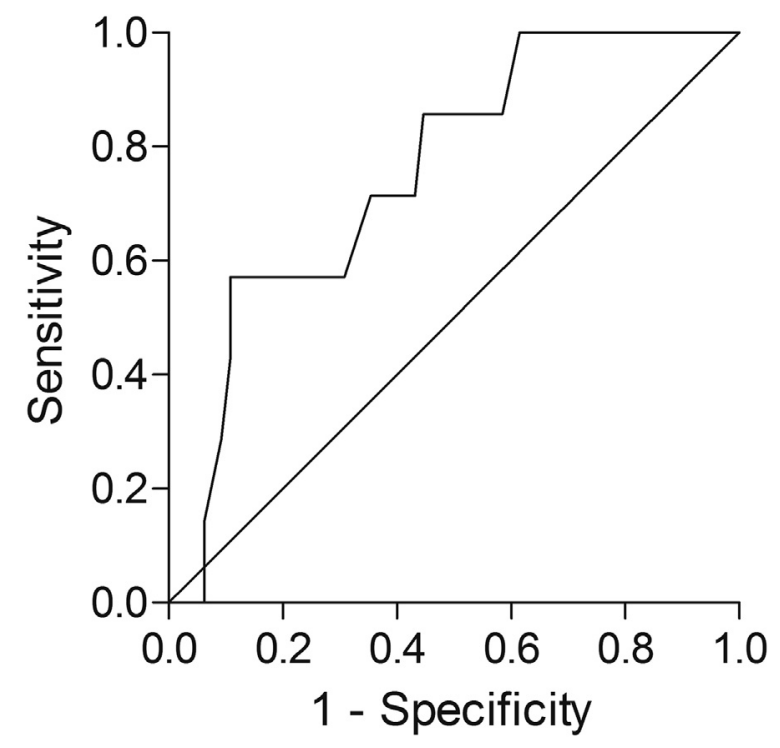

Fig. 2. ROC analysis for predicting postoperative complications from iSWT distance. Abbreviations: iSWT $=$ incremental shuttle walk test; $\mathrm{ROC}=$ receiver operating characteristic.
The presence of comorbidities, identification via the general practitioner, a higher age, a lower functional exercise capacity, a lower functional mobility and physical activity level, and a higher level of perceived fatigue were associated with a longer time to recovery of physical functioning $(P<0.200)$. Previous literature already showed the role of preoperative physical fitness and physical activity and its relation with postoperative outcomes [26,27]. Feeney et al. showed that patients who developed a postoperative pulmonary complication after an esophagectomy had a lower preoperative physical activity level $(20 \pm 13.7 \mathrm{~min} /$ day versus $36 \pm 20.7 \mathrm{~min} /$ day, $P=0.010$ ) [26]. The study of Dronkers et al. showed an independent association between adequate preoperative physical activity level (OR of 5.5, 95\% confidence interval of 1.400-21.900) and short-term mortality [27].

Our results showed a statistically significant shorter time to recovery of physical functioning for patients that were identified via the national screening program and patients that underwent laparoscopic surgery. Previous literature comparing laparoscopic surgery with open surgery also showed statistically significant differences in length of stay and other postoperative outcomes, with a higher overall morbidity rate, more complications, and a higher mortality rate in patients that underwent open surgery $[28,29]$. Patients identified via the national screening program (early inclusion) tended to be younger and fitter. Thereby, these patients had less disease-related complaints and a better TNM classification, because of the early stage of the disease. The earlier disease stage increases the options for a laparoscopic procedure, which is usually less invasive and associated with a faster medical and recovery of physical functioning $[28,29]$. In our patient population, the percentage of laparoscopic procedures was $89.7 \%$ in the group of patients that was identified via the national screening program (versus $72.2 \%$ in the group identified via the general practitioner). 


\section{Lessons learned}

We studied patients scheduled for colorectal resection, but the used methods could probably be translated to other surgical populations as well. Our data showed statistically significant associations between functional exercise capacity, Charlson comorbidity index, level of perceived fatigue, and level of physical activity, and postoperative outcomes; however, data could not be used to develop a clear prediction rule that can sufficiently explain the variance in postoperative outcomes. A larger patient population is necessary to make a valid prediction model and this study may be seen as the groundwork hereto. A multicenter study with four hospitals has recently started in the Netherlands.

An additional analysis was performed to explore the association between individual independent variables and desirable postoperative outcomes (no complications and a shorter time to recovery of physical functioning). Analysis showed that a higher body mass index, identification via the national screening program, and a higher preoperative physical activity level were associated with no occurrence of surgical complications. A higher functional exercise capacity was associated with no occurrence of non-surgical complications. A laparoscopic procedure, a lower preoperative perceived level of fatigue and a higher preoperative level of physical activity were associated with a shorter time to recovery of physical functioning ( $\leq 4$ days).

\section{Conclusion}

The current study revealed associations between preoperative physical fitness and postoperative outcome in patients with colorectal cancer scheduled for resection. A complete preoperative evaluation is valuable for patients and their caregivers and can ensure a quick start for appropriate preoperative interventions. Finally, it seems of interest to explore which (preoperative) variables can predict desirable postoperative outcomes. If preoperative parameters can distinguish patients not at risk from the total population, this group can be in- and/or excluded from additional preoperative interventions.

\section{Acknowledgements}

We are very grateful to Christel Gielen and Eveline Smeets (Maastricht Oncology Center, center for research and treatment of cancer, Maastricht $\mathrm{UMC}+$ ) for guiding and referring the patients to our physical therapy department.

\section{Appendix A. Supplementary data}

Supplementary data related to this article can be found at http://dx.doi.org/10.1016/j.ejso.2017.08.012.

\section{Funding}

Aniek Heldens, PT, MSc was supported by unconditional research grant from the Maastricht University Medical Center (Maastricht UMC+).

\section{Conflict of interest}

The authors declare no conflict of interest.

\section{References}

[1] Dutch Institute for Clinical Auditing (DICA) Leiden. DICA Jaarrapportage 2015: DSCA. 2015. accessed november 2016, http://www. clinicalaudit.nl/jaarrapportage/2015/dsca.html.

[2] Andreoni B, Chiappa A, Bertani E, Bellomi M, Orecchia R, Zampino M, et al. Surgical outcomes for colon and rectal cancer over a decade: results from a consecutive monocentric experience in 902 unselected patients. World J Surg Oncol 2007;5(73).

[3] Burns EM, Bottle A, Aylin P, Darzi A, Nicholls RJ, Faiz O. Variation in reoperation after colorectal surgery in England as an indicator of surgical performance: retrospective analysis of Hospital Episode Statistics. Br Med J 2011;343(4836).

[4] Snowden CP, Prentis J, Jacques B, Anderson H, Manas D, Jones D, et al. Cardiorespiratory fitness predicts mortality and hospital length of stay after major elective surgery in older people. Ann Surg 2013; 257(6):999-1004.

[5] West MA, Lythgoe D, Barben CP, Noble L, Kemp GJ, Jack S, et al. Cardiopulmonary exercise variables are associated with postoperative morbidity after major colonic surgery: a prospective blinded observational study. Br J Anaesth 2014;112(4):665-71.

[6] West MA, Parry MG, Lythgoe D, Barben CP, Kemp GJ, Grocott MP, et al. Cardiopulmonary exercise testing for the prediction of morbidity risk after rectal cancer surgery. Br J Surg 2014;101(9): 1166-72.

[7] Levett DZ, Grocott MP. Cardiopulmonary exercise testing for risk prediction in major abdominal surgery. Anesthesiol Clin 2015; $33(1): 1-16$

[8] Hennis PJ, Meale PM, Grocott MP. Cardiopulmonary exercise testing for the evaluation of perioperative risk in non-cardiopulmonary surgery. Postgrad Med J 2011;87(1030):550-7.

[9] Jack S, West MA, Raw D, Marwood S, Ambler G, Cope TM, et al. The effect of neoadjuvant chemotherapy on physical fitness and survival in patients undergoing oesophagogastric cancer surgery. Eur J Surg Oncol 2014;40(10):1313-20.

[10] Nutt CL, Russell JC. Use of the pre-operative shuttle walk test to predict morbidity and mortality after elective major colorectal surgery. Anaesthesia 2012;67:839-49.

[11] Struthers R, Erasmus P, Holmes K, Warman P, Collingwood A, Sneyd JR. Assessing fitness for surgery: a comparison of questionnaire, incremental shuttle walk, and cardiopulmonary exercise testing in general surgical patients. Br J Anaesth 2008;101(6): 774-80.

[12] Huisman MG, van Leeuwen BL, Ugolini G, Montroni I, Spiliotis J, Stabilini C, et al. "Timed up \& Go": a screening tool for predicting 30-day morbidity in onco-geriatric surgical patients? A multicenter cohort study. PLoS One 2014;9(1).

[13] Reddy S, Contreras CM, Singletary B, Bradford TM, Waldrop MG, Mims AH, et al. Timed stair climbing is the single strongest predictor of perioperative complications in patients undergoing abdominal surgery. J Am Coll Surg 2016;222(4):559-66.

[14] Dong J, Mao Y, Li J, He J. Stair-climbing test predicts postoperative cardiopulmonary complications and hospital stay in patients with non-small cell lung cancer. Med Sci Monit 2017;23:1436-41. 
[15] Hoogeboom TJ, Dronkers JJ, Hulzebos EH, van Meeteren NL. Merits of exercise therpay before and after major surgery. Curr Opin Anaesthesiol 2014;27(2):161-6.

[16] Hulzebos EH, van Meeteren NL. Making the elderly fit for surgery. Br J Surg 2016;103(2):12-5.

[17] Shields RK, Enloe LJ, Evans RE, Smith KB, Steckel SD. Reliability, validity, and responsivesness of functional tests in patients with total joint replacement. Phys Ther 1995;75(3):176-9.

[18] Dindo D, Demartines N, Clavien PA. Classification of surgical complications: a new proposal with the evaluation in a cohort of 6336 patients and results of a survey. Ann Surg 2004;240(2): $205-13$.

[19] Bradley J, Howard J, Wallace E, Elborn S. Validity of a modified shuttle walk test in adult cystic fibrosis. Thorax 1999;54: 437-9.

[20] Singh SJ, Morgan MDL, Scott S, Walters D, Hardman AE. Development of a shuttle walking test of disability in patients with chronin airways obstruction. Thorax 1992;47:1019-24.

[21] Parreira VF, Janaudis-Ferreira T, Evans RA, Mathur S, Goldstein RS, Brooks D. Measurement properties of the incremental shuttle walk test. A systematic review. Chest 2014;145(6):1357-69.

[22] Fess E. Grip strength. Clinical assessment recommendations. 2nd ed. Chicago: American Society of Hand Therapists; 1992. p. 41-5.
[23] Peolsson A, Hedlund R, Oberg B. Intra- and inter-tester reliability and reference values for hand strength. J Rehabil Med 2001;33(1):36-41.

[24] Gautschi OP, Corniolam MV, Joswig H, Smoll NR, Chau I, Jucker D, et al. The timed up and go test for lumbar degenerative disc disease. J Clin Neurosci 2015;22:1943-8.

[25] Stel VS, Smit JH, Pluijm SM, Visser M, Deeg DJ, Lips P. Comparison of the LASA physical activity questionnaire with a 7-day diary and pedometer. J Clin Epidemiol 2004;57:252-8.

[26] Feeney C, Reynolds JV, Hussey J. Preoperative physical activity levels and postoperative pulmonary complications post-esophagectomy. Dis Esophagus 2011;24(7):489-94.

[27] Dronkers JJ, Chorus AM, van Meeteren NL, Hopman-Rock M. The association of pre-operative physical fitness and physical activity with outcome after scheduled major abdominal surgery. Anaesthesia 2013 Jan;68(1):67-73.

[28] Vallribera Valls F, Landi F, Espín Basany E, Sánchez García JL, Jiménez Gómez LM, Martí Gallostra M, et al. Laparoscopy-assisted versus open colectomy for treatment of colon cancer in the elderly: morbidity and mortality outcomes in 545 patients. Surg Endosc 2014;28(12):3373-8.

[29] Kennedy GD, Rajamanickam V, O'connor ES, Loconte NK, Foley EF, Leverson G, et al. Optimizing surgical care of colon cancer in the older adult population. Ann Surg 2011;253(3):508-14. 